\title{
Density dependence on tree survival in an old-growth temperate forest in northeastern China
}

\author{
Jian ZHANG ${ }^{1,2}$, Zhanqing HAO ${ }^{1 *}$, I.-Fang SuN ${ }^{3}$, Bo SonG ${ }^{4}$, Ji YE ${ }^{1,2}$, Buhang LI ${ }^{1,2}$, Xugao WANG ${ }^{1}$ \\ ${ }^{1}$ Institute of Applied Ecology, Chinese Academy of Sciences, Shenyang 110016, PR China \\ ${ }^{2}$ Graduate University of Chinese Academy of Sciences, Beijing 100049, PR China \\ ${ }^{3}$ Center for Tropical Ecology and Biodiversity, Tunghai University 40704, Taichung, China \\ ${ }^{4}$ Belle W. Baruch Institute of Coastal Ecology and Forest Science, Clemson University, Georgetown, South Carolina 29442, USA
}

(Received 4 June 2008; accepted 5 October 2008)

Keywords: competition / density-dependent mortality / neighborhood effects / spatial pattern analysis / temperate forest

Mots-clés : compétition / mortalité dépendante de la densité / effets du voisinage / analyse du modèle spatial / forêt tempérée

\begin{abstract}
- Density dependence is a major mechanism for shaping plant communities. However, its role in regulating diverse, mixed natural tree communities is less certain.

- In this study we investigated density-dependent effects in a large-scale ( 25 ha) old-growth temperate forest in northeastern China. Spatial patterns of neighborhood distribution in the plot were analyzed using various methods for inferring competition, including (1) pair correlation function to determine spatial patterns of pre-mortality and post-mortality and (2) neighborhood analysis of individuals to examine the extent to which tree survival is correlated with other covariates.

- Results showed that, for common species, 3 of 5 canopy species and 3 of 8 midstory and understory species were random in mortality. Negative density-dependent mortality was not found when trees reach $1 \mathrm{~cm}$ in DBH. There was no significant correlation for canopy species between tree survival and conspecific abundance, but largely positive correlations for midstory and understory species. In contrast, tree survival was found to negatively correlate with conspecific basal area for most species, indicating strong intraspecific competition. No strong interspecific density dependence was found in the forest.
\end{abstract}

Résumé - La survie des arbres dépend de la densité dans une ancienne forêt tempérée du nordest de la Chine.

- La dépendance par rapport à la densité est un important mécanisme pour la formation des communautés végétales. Toutefois, son rôle dans la régulation de diverses communautés mélangées d'arbre est moins certain.

- Dans cette étude, nous avons enquêté sur les effets densité-dépendance à une grande échelle (25 ha) dans une ancienne forêt tempérée, dans le nord de la Chine. Les modes de distribution spatiale de voisinage ont été analysés en utilisant diverses méthodes pour estimer la concurrence, y compris : (1) des paires de fonction de corrélation afin de déterminer les structures spatiales de pré et postmortalité et (2) l'analyse du voisinage des individus pour examiner dans quelle mesure la survie de l'arbre survivant est corrélée avec d'autres variables.

- Les résultats ont montré que, pour les espèces communes, 3 des 5 espèces de la canopée et 3 des 8 de l'étage moyen et du sous-étage, la mortalité était aléatoire. Aucune mortalité densité-dépendante négative n'a été détectée lorsque les arbres atteignent $1 \mathrm{~cm}$ de diamètre à hauteur d'homme. Il n'y avait pas de corrélation significative pour les espèces de la canopée entre la survie des arbres et l'abondance conspécifique, mais il y avait des corrélations positives pour l'étage moyen et le sous-étage.

- En revanche, la survie des arbres était corrélée négativement avec la surface terrière conspécifique pour la plupart des espèces, indiquant une forte concurrence intraspécifique. Aucune dépendance visible de la densité interspécifique n'a été détectée dans la forêt.

\footnotetext{
*Corresponding author: hzq@iae.ac.cn
} 


\section{INTRODUCTION}

Plants respond to their local neighborhood for diverse resources, such as light (Getzin et al., 2006; He and Duncan, 2000), water (Engelbrecht et al., 2007), and soil nutrients (John et al., 2007; Wallace et al., 2007). Neighborhood processes can influence survival, recruitment, and growth of plant species positively through facilitation (Wills et al., 1997) or negatively by competition (Getzin et al., 2006; Gratzer and Rai, 2004), and indirectly by specialist herbivores and pathogens (Dobbertin et al., 2001; Gunton and Kunin, 2007; Hyatt et al., 2003; Janzen, 1970; Peters, 2003). These processes together to regulate species coexistence (Pacala, 1989; Peters, 2003; Volkov et al., 2005; Wills et al., 2006).

Field studies have demonstrated density dependence of varying extents in different species (e.g., He and Duncan, 2000; Hubbell and Foster, 1986; Kenkel, 1988; Peters, 2003; Wills and Condit, 1999; Wills et al., 1997). However, it is still unclear to what degree and spatial scale that density-dependent interactions among species may play a role in plant populations, especially in diverse, mixed tree communities (Gunton and Kunin, 2007; John et al., 2002). How prevalent is density dependence among trees? How does it change with spatial scales? How does it influence species composition, density and survival, and how is it in turn influenced by them? Wills and Condit (1999) examined 100 common species in three permanent plots in tropical forest, and found that density-dependent mortality was largely random after trees reached larger sizes. Similar results were found by other researchers (e.g., Connell et al., 1984; Harms et al., 2000; Hubbell et al., 1990). However, Peters (2003) investigated the roles of neighborhood crowding on tree mortality in two tropical forest plots, and suggested that density-dependent mortality may be important even for very large trees. John et al. (2002) demonstrated that mortality for trees of 1-10 cm DBH was negatively correlated with conspecific density in a dry tropical forest which is moderately disturbed by human-induced dry-season grass fires, while mortality for trees of $>10 \mathrm{~cm} \mathrm{DBH}$ trees was positively correlated. Hyatt et al. (2003) conducted a meta-analysis of density dependence in 40 studies on seed and seedling predation, and concluded that there was no general support for density dependence. In Barro Colorado Island of Panama, Wills et al. (1997) found that intraspecific effects were stronger than interspecific effects. He and Duncan (2000) examined densitydependent effects in an old-growth temperate forest in the Pacific Northwest and concluded that both intra- and interspecific density-dependent mortality were important, with the intensity changing with species. John et al. (2002) found that mortality was largely unaffected by the basal area and abundance of heterospecific trees in a dry tropical forest.

Research about density dependence has largely been focused on exploring either the general mechanisms for tree communities (e.g., Hubbell and Foster, 1986; Hyatt et al., 2003; Peters, 2003; Wills and Condit, 1999; Wills et al., 1997) or a few dominant species (e.g., Getzin et al., 2006; He and Duncan, 2000). Few studies have investigated competition of trees of different growth forms. This is important because the extent and spatial scale of the density-dependent effect may also change with growth forms (Gratzer and Rai, 2004). Knowledge of the relative importance of density dependence in different growth forms can help understand plant population dynamics and species coexistence.

Our objectives of this study were to investigate the importance of density-dependent tree survival in an old-growth temperate forest, to explore the extent and spatial scale at which density dependence operates and to compare densitydependent effects for species of different growth forms.

\section{METHODS}

\subsection{Study site}

The study site is located in the Changbaishan (Mountain) Nature Reserve along the border of China and North Korea extending from $127^{\circ} 42^{\prime}$ to $128^{\circ} 17^{\prime} \mathrm{E}$ and $41^{\circ} 43^{\prime}$ to $42^{\circ} 26^{\prime} \mathrm{N}$. The reserve was established in 1960 and is part of the World Biosphere Reserve Network. The reserve is about 200000 ha and elevation ranges from $740 \mathrm{~m}$ to $2691 \mathrm{~m}$. Five vegetation zones can be identified: aspen-white birch (Populus davidiana and Betula platyphylla) forest, broad-leaved Korean pine ( $P i$ nus koraiensis) mixed forest, spruce-fir (Picea jezoensis and Abies nephrolepis) forest, subalpine birch (B. ermanii) forest, and alpine tundra (Yang et al., 1985). The four forest vegetation zones are representative of temperate and boreal forests found across northeastern China.

Our study site belongs to broad-leaved Korean pine mixed forest, an old-growth, mixed temperate forest. It is the dominant vegetation type in northeastern China and well-known for high species richness and unique species composition in temperate forests (Yang and Xu, 2003). The climate is characterized by low temperate, high precipitation, and strong wind with the prevailing direction of west-south-west (Yang et al., 1985). Mean annual temperature is $3.3^{\circ} \mathrm{C}$ (January $-16.5^{\circ} \mathrm{C}$, August $20.5^{\circ} \mathrm{C}$ ). Mean annual precipitation is $671.9 \mathrm{~mm} /$ year, most of which occurs between June and August. The soil is classified as dark brown forest soil. The stand age is about 300 years. There is little human disturbance in the core zone because Changbai Mountain was protected as the legendary birthplace of the imperial family during the Qing Dynasty (A.D.1644-1911), and as the national natural reserve at the beginning of the 1960s. Vertical structure of the forest can be identified. The canopy layer is $20-35 \mathrm{~m}$ tall, and the main tree species are Korean pine, Amur linden (Tilia amurensis), Mongolian Oak (Quercus mongolica), Manchurian ash (Fraxinus mandshurica), and Japanese elm (Ulmus japonica). Main species of the midstory layer (10-20 m tall) include Mono maple (Acer mono), Purplebloom maple (A. pseudosiebodianum), Manchustriple maple (A. tegmentosum), and Amur maackia (Maackia Amurensis). Understory layer is below $10 \mathrm{~m}$, includes Manchurian hazelnut (Corylus mandshurica), Barbedvein maple (A. barbinerve), and European bird cherry (Prunus padus). 


\subsection{Data collection}

In 2004 , a 25 ha $(500 \times 500 \mathrm{~m})$ broad-leaved Korean pine mixed forest plot was established. Following the field protocol of the Center for Tropical Forest Science of the Smithsonian Tropical Research Institute (Condit, 1998), the plot was divided into $625,20 \times 20 \mathrm{~m}$ subplots, and then each $20 \times 20 \mathrm{~m}$ subplot was divided into $16,5 \times 5 \mathrm{~m}$ quadrates. Our survey was based on these quadrates. All living and dead trees with diameters at breast height $\geq 1 \mathrm{~cm}$ were stem-mapped and identified to species. The total number of individuals in the census was 45384 , including 38902 living trees and 6482 dead trees. These individuals belong to 52 species, 32 genera, and 18 families (Hao et al., 2007).

\subsection{Data analysis}

To test the density-dependent effects on tree survival, spatial patterns of pre-mortality (all living and dead trees) were reconstructed using the slow decomposition rate of dead trees in the plot (Getzin et al., 2006; He and Duncan, 2000; Kenkel, 1988). We chose 13 tree species that have at least 50 dead individuals with $\geq 1 \mathrm{~cm} \mathrm{DBH}$ for the analysis (Tab. I). Fifty dead trees were chosen to ensure a sufficient sample size for statistical analysis. The 13 selected species accounted for $93 \%$ of the total abundance and for $94 \%$ of the total basal area. According to their growth forms, the 13 tree species were divided into 3 groups, canopy species, midstory species, and understory species independently. We tested if the difference of density dependent effects exists in different growth forms.

\subsubsection{Spatial pattern analysis}

Pair-correlation function $g(r)$ was used to analyze spatial patterns of pre- and post-mortality based on point-to-point distance (Stoyan and Stoyan, 1994; Wiegand and Moloney, 2004). $g(r)=1$ indicates complete spatial randomness, $g(r)>1$ aggregation, while $g(r)<1$ regularity. The method is related to the widely used Ripley's $K$ function (Ripley, 1981) and mark correlation functions (Stoyan and Stoyan, 1994). Compared with Ripley's $K$ function, pair-correlation function $g(r)$ isolates specific distance classes by replacing the circles used for calculation of Ripley's $K$ function with rings, and using the mean number of neighbors in a ring of radius $r$ and ring width around an individual (Wiegand and Moloney, 2004). Thus it can analyze spatial patterns derived from ecological processes more intuitively (Wiegand and Moloney, 2004).

To test the hypothesis of random mortality that spatial distribution of pre-mortality does not differ from that of post-mortality, and the hypothesis that there is no difference between the spatial patterns of each species belonging to different growth forms, complete spatial random (CSR), heterogeneous Poisson process, and random labeling null models were chosen for these analyses (Getzin et al., 2006; Wiegand and Moloney, 2004).
Analyzing the pattern of pre-mortality, we chose the basic null model by visualizing the stem distribution of different species first. CSR was chosen as the null model when there is no clearly visible cluster in the pattern. If a pattern is heterogeneous (i.e. only distributed in some parts of the plot), a heterogeneous Poisson process was chosen as the alternative to CSR (Wiegand and Moloney, 2004). A univariate random labeling null model was used to investigate whether the postmortality pattern of one species is a random subset of the entire pre-mortality pattern of the species. If intraspecific competition leads to a more regular post-mortality pattern of surviving trees, conspecific negative density-dependent mortality is confirmed. The test was conducted by computing the function $g_{11}(r)$ from the observed data, then randomly re-sampling sets of dead trees from the pattern of pre-mortality to generate the confidence limits.

Spatial point pattern analysis was computed using the gridbased software Programita (Wiegand and Moloney, 2004). Ninety-nine Monte Carlo simulations were used to generate the $99 \%$ confidence envelopes.

\subsubsection{Neighborhood analysis}

An individual-based approach was used to determine the influence of several factors, including the basal area of focal trees, con- and heterospecific neighborhoods, con- and heterospecific basal area, number of neighborhood species and elevation, on tree survival (He and Duncan, 2000; Peters, 2003). Elevation for each individual was estimated based on each $20 \times 20 \mathrm{~m}$ grid, using kriging interpolation implemented with ARCGIS software. For each individual of the 13 species in the plot, neighborhoods with radii of 5,10,15, and $20 \mathrm{~m}$ from the focal tree were defined, and the values for each factor were calculated. Only those trees with a distance greater than or equal to the neighborhood radius from the plot edges were included in these analyses.

For each species and neighborhood size, multiple logistic regressions were used to test for the relationship among tree survival and the above-mentioned factors (He and Duncan, 2000). In order to reduce the possibility of reaching spurious conclusions, the regression coefficients from the real plot data were compared with a set of regression coefficients calculated by the randomization approach of Mitchell-Olds (1987). The randomization approach was carried out by constructing a series of randomized data sets in which the location of all trees within each species was retained while reassigning the survival fate of each tree to a randomly selected individual of the same species (Peters, 2003; Wills et al., 1997). Regression coefficients were calculated for each randomized data set. The randomization procedure was repeated 2000 times. Then, the change in deviance from the real regression coefficient was calculated to determine the significance of the observed relationship. 


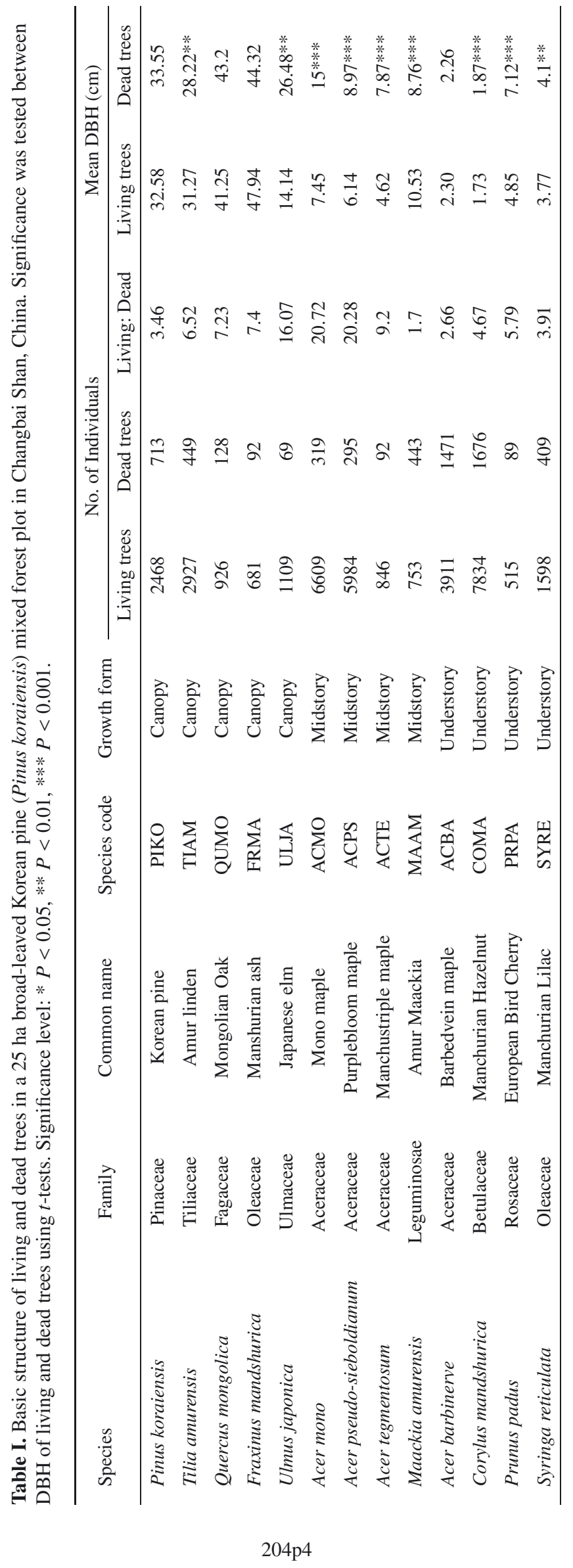




\section{RESULTS}

\subsection{Composition and size structure}

Understory species COMA, midstory species ACMO and ACPS were the most abundant species in the plot (Tab. I), while understory species COMA, ACBA, and canopy species PIKO suffered most mortality. The number of dead trees of 4 understory species accounted for $58.4 \%$ of all dead trees. In all species, the abundance of living trees was always greater than that of their dead trees. This was particularly true for ACMO, ACPS, and ULJA.

In a pooled analysis of all species, three size-class groups showed different patterns (Fig. 1). The relative proportion and total abundance of living and dead trees of the canopy species was uniform. However, the midstory and understory species were mostly concentrated in the smallest size classes $(\leq 10 \mathrm{~cm}$ and $\leq 3 \mathrm{~cm}$ in $\mathrm{DBH}$, respectively).

There were considerable differences among the mean DBH of living and dead trees in the three growth forms (Tab. I). Nine of the 13 abundant species have significantly larger DBH for living trees than that of dead trees. The remaining four species do not show difference in DBH between living and dead trees. They are three canopy species (PIKO, QUMO, and FRMA) and one understory species (ACBA).

\subsection{Spatial pattern analysis}

Canopy species PIKO, FRMA, and ULJA were strongly aggregated at scales up to $50 \mathrm{~m}$ in pre-mortality, while random in post-mortality (Tab. II and Fig. 2). TIAM in premortality were mainly aggregated at scales $\leq 25 \mathrm{~m}$, while aggregated at scales $\leq 5 \mathrm{~m}$ and random at other scales in postmortality. QUMO were random at almost all scales either in pre-mortality or in post-mortality.

To the midstory and understory species (Tab. II, Fig. 2), 6 species were mainly aggregated in pre-mortality, while other 2 species random. For post-mortality trees, 6 species were mainly random in post-mortality, while PRPA and SYRE were aggregated at small scales. Only ACMO was aggregated at scales up to $50 \mathrm{~m}$ (Fig. 2), indicating evidence of positive density-dependent mortality.

\subsection{Neighborhood effects on tree survival}

Basal area of focal trees (BA). Tree survival and BA were significantly negatively correlated for 7 of the 13 species (Tab. III). Three species had positive correlation with their survival. For canopy species, the survival of PIKO and ULJA decreased strongly with increasing BA, but the survival of TIAM and FRMA increased. For midstory species, only MAAM showed significant positive correlation, while other species were negatively correlated. For understory species, the survival of COMA and SYRE decreased strongly with increasing BA.
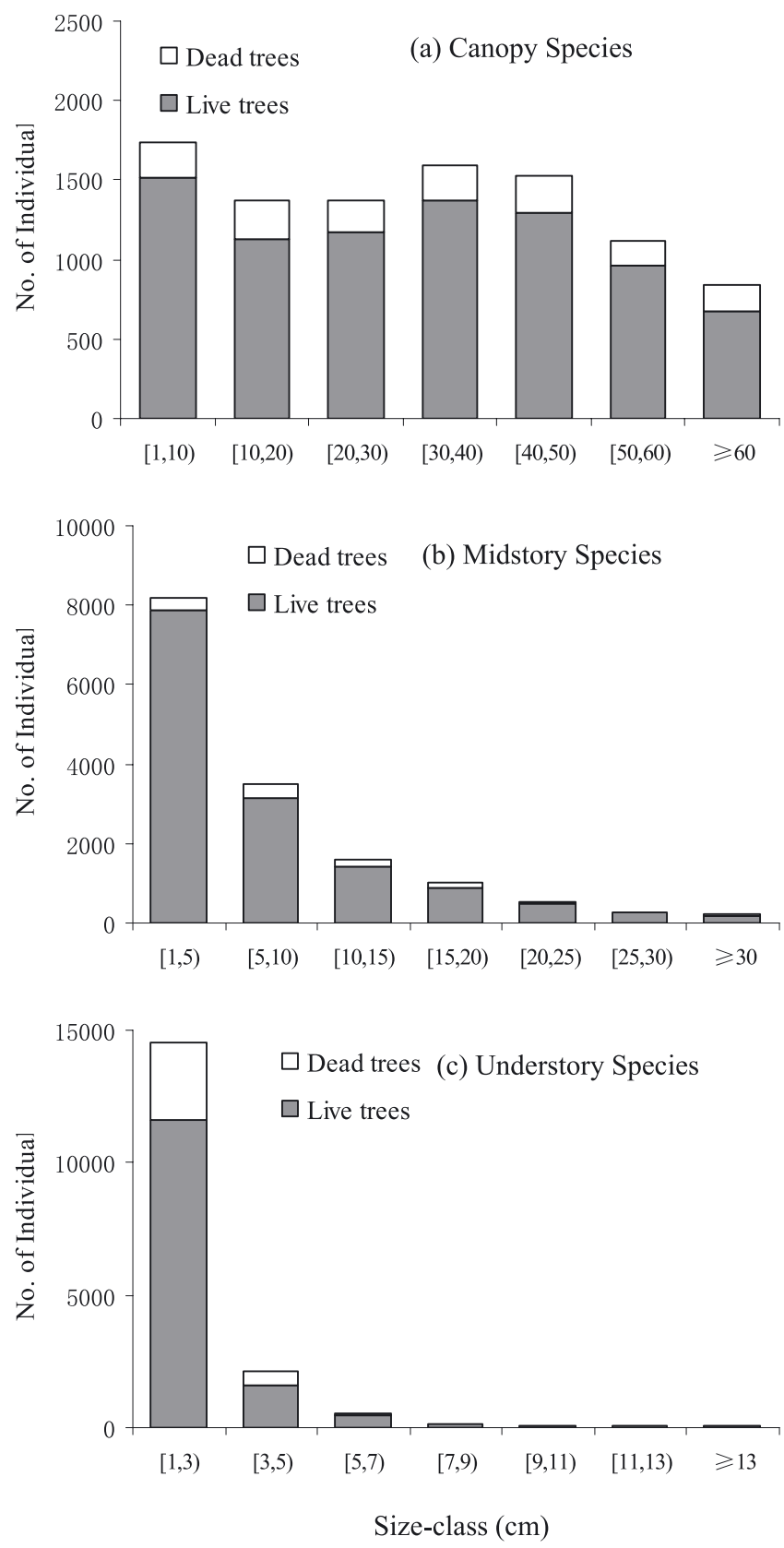

Figure 1. DBH distributions of living and dead trees for $(a)$ the five most abundant canopy species, $(b)$ the four most abundant midstory species, and $(c)$ the four most abundant understory species.

Conspecific abundance (CA). There were very few significant relationships between the survival of canopy species and CA (Tab. III). For midstory and understory species, tree survival generally increased with increasing CA at each neighborhood radius.

Heterospecific abundance (HA). No significant correlation was found for 8 species at any neighborhood radius (Tab. III). For canopy species, the survival of ULJA showed positive correlation at a radius of $5 \mathrm{~m}$. For midstory species, only the survival of ACPS had largely positive correlation with HA. 
Table II. Univariate analysis of the pre- and post-mortality patterns of the 13 species, using point pattern analysis method $g(r)$. Some specific examples can be found in Figure 2. In the table, "+/+" means aggregation of pre- and post-mortality, "r/+" means pre-mortality random vs. post-mortality aggregation, “+/-" means pre-mortality aggregation vs. post-mortality regularity, etc. See Table 1 for species codes.

\begin{tabular}{|c|c|c|c|c|c|c|c|c|c|c|}
\hline & \multicolumn{10}{|c|}{ Scale (m) } \\
\hline & $0-5$ & $6-10$ & $11-15$ & $16-20$ & $21-25$ & $26-30$ & $31-35$ & $36-40$ & $41-45$ & $46-50$ \\
\hline \multicolumn{11}{|l|}{ Canopy species } \\
\hline PIKO & $+/ \mathrm{r}$ & $+/ \mathrm{r}$ & $+/ \mathrm{r}$ & $+/ \mathrm{r}$ & $+/ \mathrm{r}$ & $+/ \mathrm{r}$ & $+/ \mathrm{r}$ & $+/ \mathrm{r}$ & $+/ \mathrm{r}$ & $+/ \mathrm{r}$ \\
\hline TIAM & $+/+$ & $+/ \mathrm{r}$ & $+/ \mathrm{r}$ & $+/ \mathrm{r}$ & $+/ \mathrm{r}$ & $\mathrm{r} / \mathrm{r}$ & $\mathrm{r} / \mathrm{r}$ & $\mathrm{r} / \mathrm{r}$ & $\mathrm{r} / \mathrm{r}$ & $+/ \mathrm{r}$ \\
\hline QUMO & $\mathrm{r} /-$ & $\mathrm{r} / \mathrm{r}$ & $\mathrm{r} / \mathrm{r}$ & $\mathrm{r} / \mathrm{r}$ & $\mathrm{r} / \mathrm{r}$ & $\mathrm{r} / \mathrm{r}$ & $\mathrm{r} / \mathrm{r}$ & $\mathrm{r} / \mathrm{r}$ & $\mathrm{r} / \mathrm{r}$ & $\mathrm{r} / \mathrm{r}$ \\
\hline FRMA & $+/ \mathrm{r}$ & $+/ \mathrm{r}$ & $+/ \mathrm{r}$ & $+/ \mathrm{r}$ & $+/ \mathrm{r}$ & $+/ \mathrm{r}$ & $+/+$ & $+/ \mathrm{r}$ & $+/ \mathrm{r}$ & $+/ \mathrm{r}$ \\
\hline ULJA & $+/ \mathrm{r}$ & $+/ \mathrm{r}$ & $+/ \mathrm{r}$ & $+/ \mathrm{r}$ & $+/ \mathrm{r}$ & $+/ \mathrm{r}$ & $+/ \mathrm{r}$ & $+/ \mathrm{r}$ & $+/ \mathrm{r}$ & $+/ \mathrm{r}$ \\
\hline \multicolumn{11}{|l|}{ Midstory species } \\
\hline ACMO & $+/+$ & $+/+$ & $+/+$ & $+/+$ & $+/+$ & $+/+$ & $+/+$ & $+/+$ & $+/+$ & $+/+$ \\
\hline ACPS & $+/ \mathrm{r}$ & $+/ \mathrm{r}$ & $+/+$ & $+/ \mathrm{r}$ & $+/ \mathrm{r}$ & $+/ \mathrm{r}$ & $+/ \mathrm{r}$ & $+/ \mathrm{r}$ & $+/ \mathrm{r}$ & $+/ \mathrm{r}$ \\
\hline ACTE & $+/ \mathrm{r}$ & $+/ \mathrm{r}$ & $+/ \mathrm{r}$ & $+/ \mathrm{r}$ & $+/ \mathrm{r}$ & $\mathrm{r} /+$ & $\mathrm{r} / \mathrm{r}$ & $-/ \mathrm{r}$ & $-/+$ & $\mathrm{r} / \mathrm{r}$ \\
\hline MAAM & $\mathrm{r} / \mathrm{r}$ & $\mathrm{r} /+$ & $\mathrm{r} / \mathrm{r}$ & $\mathrm{r} /+$ & $\mathrm{r} / \mathrm{r}$ & $\mathrm{r} /+$ & $\mathrm{r} /+$ & $\mathrm{r} / \mathrm{r}$ & $\mathrm{r} /+$ & $\mathrm{r} / \mathrm{r}$ \\
\hline \multicolumn{11}{|l|}{ Understory species } \\
\hline ACBA & $+/ \mathrm{r}$ & $+/ \mathrm{r}$ & $+/ \mathrm{r}$ & $+/ \mathrm{r}$ & $+/ \mathrm{r}$ & $+/ \mathrm{r}$ & $+/ \mathrm{r}$ & $+/ \mathrm{r}$ & $+/ \mathrm{r}$ & $+/ \mathrm{r}$ \\
\hline COMA & $+/ \mathrm{r}$ & $+/ \mathrm{r}$ & $+/ \mathrm{r}$ & $+/ \mathrm{r}$ & $\mathrm{r} /+$ & $-1+$ & $\mathrm{r} / \mathrm{r}$ & $\mathrm{r} / \mathrm{r}$ & $\mathrm{r} / \mathrm{r}$ & $-/ \mathbf{r}$ \\
\hline PRPA & $+/+$ & $+/ \mathrm{r}$ & $+/+$ & $+/ \mathrm{r}$ & $+/ \mathrm{r}$ & $\mathrm{r} / \mathrm{r}$ & $-/ \mathrm{r}$ & $-/ \mathrm{r}$ & $-/ \mathrm{r}$ & $-/ \mathrm{r}$ \\
\hline SYRE & $+/+$ & $\mathrm{r} /+$ & $-/ \mathrm{r}$ & $\mathrm{r} / \mathrm{r}$ & $\mathrm{r} / \mathrm{r}$ & $\mathrm{r} / \mathrm{r}$ & $\mathrm{r} /-$ & $\mathrm{r} /-$ & $\mathrm{r} / \mathrm{r}$ & $\mathrm{r} /-$ \\
\hline
\end{tabular}

For understory species, the survival of COMA was largely negatively correlated with $\mathrm{HA}$ at radii of $10 \mathrm{~m}$ and $15 \mathrm{~m}$, and the survival of SYRE was positively correlated at each neighborhood radius.

Conspecific basal area $(C B)$. Negative correlations between tree survival and CB were found for 8 species, and the extent of the correlations varied with species and neighborhood distances. The survival of 3 canopy species, 2 midstory species, and 2 understory species decreased strongly with increasing $\mathrm{CB}$ at some neighborhood distances (Tab. III). Intraspecific competition of most canopy species mainly depended on the basal area, not the abundance, while conspecific basal area and abundance of most midstory and understory species played opposite roles to intraspecific competition.

Heterospecific basal area $(H B)$. As with heterospecific abundance, HB was non-significantly correlated with the survival of most species (Tab. III), implying that interspecific competition was weak for most species.

Number of species $(S P)$. There were very few significant correlations between tree survival and SP (Tab. III). Specifically, the survival of MAAM, COMA, and SYRE were positively correlated with SP at some neighbor distances.

Elevation (ELEV). The correlations between tree survival and elevation varied among species. No significant correlation can be found among the growth form and neighborhood distances.

\section{DISCUSSION}

Spatial pattern analysis of pre- and post-mortality has been used to analyze density dependence on tree survival in forests for a long time (Duncan, 1991; He and Duncan, 2000; Kenkel, 1988). Density-independent tree survival or the random mortality hypothesis predicts that the spatial patterns of postmortality of surviving trees would remain unchanged if individuals in a community have the same probability of mortality (Getzin et al., 2006). In contrast, if the post-mortality patterns become more regular than the pre-mortality pattern, conspecific density dependence on tree survival is validated. This hypothesis was not only tested in even-aged, monoculture stands (Kenkel, 1988; Newton and Jolliffe, 1998), but also in unevenaged, mixed forests (Duncan, 1991; Getzin et al., 2006; He and Duncan, 2000). About three-quarter of these cases showed that mortality was not random in space, indicating strong intraspecific competition (Silvertown and Charlesworth, 2001). In our study, pre-mortality patterns of the common species were mostly aggregated which indicated strong intraspecific competition as well. Furthermore, the pre-mortality patterns of canopy species were more aggregated than that of midstory and understory species. Similar results have been reported in many other studies (e.g., Condit et al., 2000; Salas et al., 2006). Many factors, such as limited seed dispersal (Connell et al., 1984; Grubb, 1977; Harms et al., 2000), and environmental heterogeneity (King et al., 2006; Koukoulas and Blackburn, 2005), have contributed to these patterns. On the other hand, post-mortality patterns of 3 of 5 canopy species and 3 of 8 midstory and understory species were random in mortality. Only 

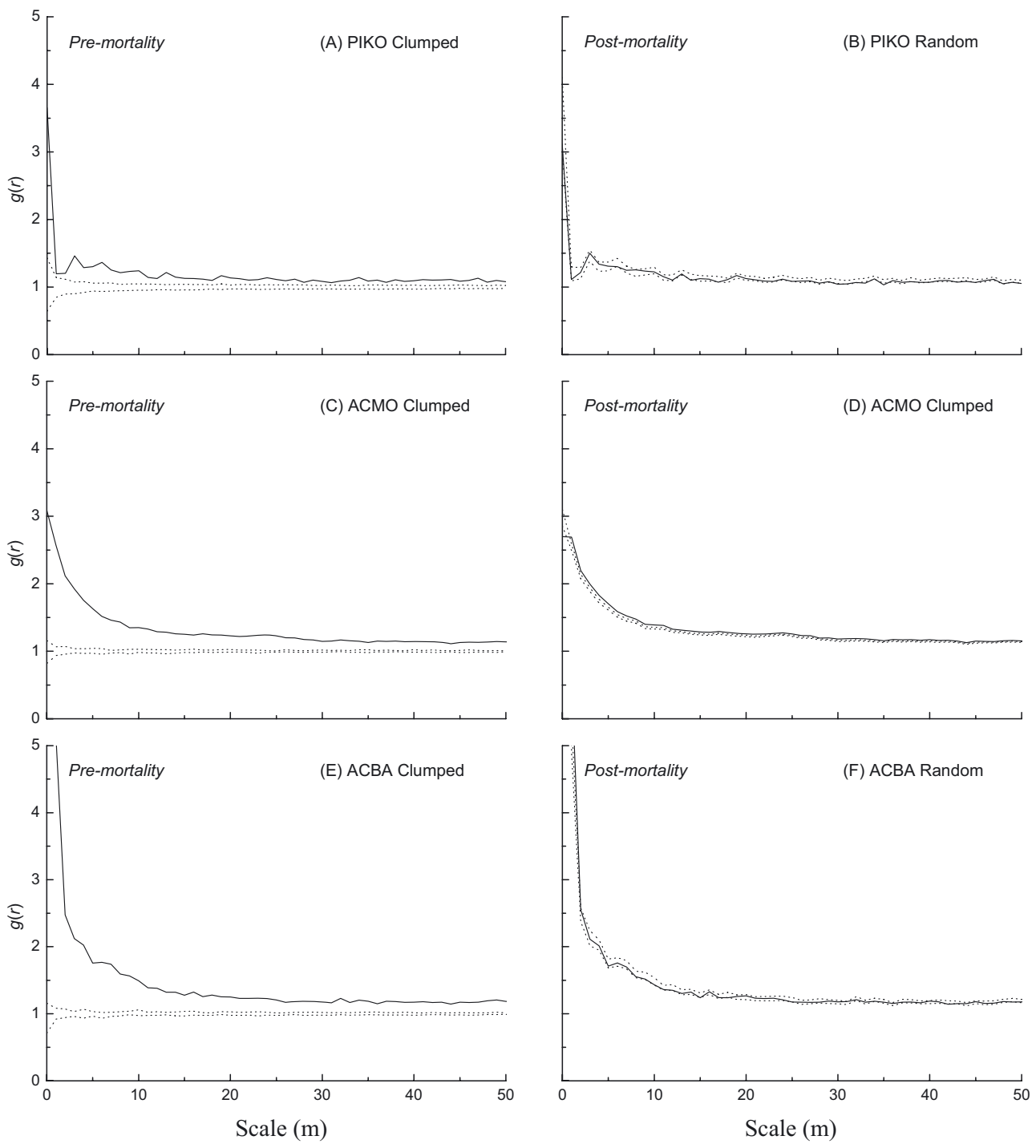

Figure 2. Univariate analysis of the pre- and post-mortality patterns of the 13 species, using point pattern analysis method $g(r)$. The results of three species are shown as examples. Complete spatial random or heterogeneous Poisson process was used for pre-mortality patterns. Univariate random labeling null model was used to investigate whether the post-mortality pattern is a random subset of the pre-mortality pattern of the species. Conspecific negative density-dependent mortality is confirmed if intraspecific competition leads to a more regular post-mortality pattern of surviving trees. The test was conducted by computing the function $g_{11}(r)$ from the observed data, then randomly re-sampling sets of dead trees from the pattern of pre-mortality to generate the confidence limits. Ninety-nine Monte Carlo simulations were used to generate the $99 \%$ confidence envelopes. Black solid lines indicate $g(r)$; thin dashed lines indicate the confidence envelope of the null model. Points above the upper envelope indicate aggregated; points below the lower envelope indicate regular. See Table I for species codes.

canopy species QUMO showed strong density dependence on the tree survival in the forest. Therefore, conspecific density dependence on tree survival can not be captured in the forest using the spatial point pattern analysis. Five of eight midstory and understory species showed significant positive density dependence on tree survival. We conclude that the factors resulting in clumping, such as limited seed dispersal and abiotic factors, may have played much more important roles than limited intraspecific density dependence in causing the clumping.

Neighborhood analysis gives us much information about density dependence on tree survival because it considers im- portant factors which indicate density-dependent effects, such as intra- and interspecific basal area, the number of species, and environmental factors (He and Duncan, 2000; Hubbell and Foster, 1986). Of the 13 most common species of our study plot, negative correlations between the survival of 9 species and the basal area of focal trees indicated that there were strong intra- and/or interspecific competition among large trees in the forest. Similar results were found when spatial associations of these species were analyzed between different size-class trees in the plot (Hao et al., 2007). Intraspecific density dependence on tree survival showed similar correlations 
Table III. Neighborhood effect on the survival of the 13 species. The table entries are results of logistic regression with 7 predictor variables at four neighborhood radii. The 7 predictor variables are basal area of the focal tree (BA), conspecific abundance (CA), heterospecific abundance (HA), conspecific basal area $(\mathrm{CB})$, heterospecific basal area (HB), number of species (SP), and the elevation (ELEV). A predictor is not shown if it is not significant at any radii. Nonsignificant correlations between tree survival and these variables are indicated by " 0 ". The signs "+", " ++ " and " +++ " indicate significant positive correlations at $\alpha$-levels $0.05,0.01$ and 0.001 , respectively. Similarly, "_" indicate negative correlations.

\begin{tabular}{|c|c|c|c|c|c|}
\hline Target species & Predictor variable & $5 \mathrm{~m}$ & $10 \mathrm{~m}$ & $15 \mathrm{~m}$ & $20 \mathrm{~m}$ \\
\hline \multicolumn{6}{|l|}{ PIKO } \\
\hline & $\mathrm{BA}$ & --- & --- & --- & --- \\
\hline & $\mathrm{CB}$ & 0 & 0 & --- & - \\
\hline & HB & ++ & 0 & - & -- \\
\hline & ELEV & - & - & 0 & 0 \\
\hline \multicolumn{6}{|l|}{ TIAM } \\
\hline & $\mathrm{BA}$ & ++ & ++ & ++ & ++ \\
\hline & $\mathrm{CB}$ & - & -- & 0 & 0 \\
\hline & ELEV & ++ & + & 0 & 0 \\
\hline \multicolumn{6}{|l|}{ QUMO } \\
\hline & $\mathrm{CA}$ & -- & 0 & 0 & 0 \\
\hline \multicolumn{6}{|l|}{ FRMA } \\
\hline & $\mathrm{BA}$ & 0 & + & + & 0 \\
\hline & HA & 0 & - & - & - \\
\hline & $\mathrm{CB}$ & - & - & -- & 0 \\
\hline & $\mathrm{HB}$ & 0 & - & - & -- \\
\hline \multicolumn{6}{|l|}{ ULJA } \\
\hline & $\mathrm{BA}$ & --- & --- & --- & --- \\
\hline & HA & + & 0 & 0 & 0 \\
\hline & $\mathrm{HB}$ & 0 & - & - & 0 \\
\hline & $\mathrm{SP}$ & - & 0 & 0 & 0 \\
\hline & ELEV & + & 0 & + & + \\
\hline \multicolumn{6}{|l|}{ ACMO } \\
\hline & BA & --- & --- & --- & --- \\
\hline & $\mathrm{CA}$ & +++ & +++ & +++ & +++ \\
\hline & $\mathrm{CB}$ & --- & - & 0 & 0 \\
\hline & ELEV & --- & -- & - & 0 \\
\hline \multicolumn{6}{|l|}{ ACPS } \\
\hline & $\mathrm{BA}$ & --- & --- & --- & --- \\
\hline & $\mathrm{CA}$ & 0 & 0 & + & 0 \\
\hline & $\mathrm{HA}$ & 0 & ++ & +++ & ++ \\
\hline & $\mathrm{CB}$ & - & 0 & 0 & 0 \\
\hline & ELEV & + & 0 & 0 & 0 \\
\hline \multicolumn{6}{|l|}{ ACTE } \\
\hline & $\mathrm{BA}$ & --- & --- & --- & --- \\
\hline & $\mathrm{CA}$ & 0 & + & + & + \\
\hline \multicolumn{6}{|l|}{ MAAM } \\
\hline & $\mathrm{BA}$ & +++ & ++ & +++ & ++ \\
\hline & $\mathrm{CA}$ & + & ++ & + & 0 \\
\hline & $\mathrm{CB}$ & 0 & -- & - & - \\
\hline & HB & - & - & 0 & 0 \\
\hline & SP & 0 & + & 0 & 0 \\
\hline & ELEV & --- & - & -- & -- \\
\hline \multicolumn{6}{|l|}{ ACBA } \\
\hline & $\mathrm{CA}$ & +++ & ++ & + & + \\
\hline & ELEV & --- & -- & -- & -- \\
\hline
\end{tabular}

Table III. Continued.

\begin{tabular}{llcccc}
\hline Target species & Predictor variable & $5 \mathrm{~m}$ & $10 \mathrm{~m}$ & $15 \mathrm{~m}$ & $20 \mathrm{~m}$ \\
\hline COMA & & & & & \\
& BA & --- & --- & --- & --- \\
& CA & +++ & +++ & ++ & +++ \\
& HA & 0 & 0 & -- & -- \\
& CB & 0 & 0 & -- & -- \\
& HB & 0 & + & 0 & 0 \\
PRPA & SP & 0 & ++ & ++ & +++ \\
& ELEV & - & - & 0 & 0 \\
& CA & & & & \\
& & + & 0 & 0 & 0 \\
& BA & & & & \\
& CA & -- & -- & -- & - \\
& HA & +++ & +++ & +++ & +++ \\
& CB & + & + & + & + \\
& SP & 0 & -- & 0 & 0 \\
& ELEV & 0 & 0 & 0 & ++ \\
& & +++ & +++ & +++ & +++ \\
\hline
\end{tabular}

with conspecific abundance as to the spatial pattern analysis. There was no significant correlation for canopy species, while mostly positive correlations for midstory and understory species existed. However, the correlations between tree survival and conspecific basal area were mostly negative, indicating strong intraspecific competition for most species in the forest. Therefore, tree size may have contributed more to intraspecific competition than tree population density. Similar results were also found in some tropical forest plots. Wills et al. (1997) examined density dependence in the 50 ha BCI moist tropical forest plot, and found that strong, intra-specific density-dependent effects on survival could regulate populations. In contrast, there was no strong interspecific density dependence found in the forest. The result was similar with that of John et al. (2002) in a 50 ha dry tropical forest plot in Mudumalai, India. In addition, elevation was also a non-negligible variable for tree survival. Tree survival of 9 species was correlated with elevation. The correlations for canopy species were much lower than that for midstory and understory species, indicating that canopy species perhaps have broad niches for their survival (Hao et al., 2007; Xu, 2001).

In summary, the results of this study on an old-growth temperate forest suggest that density-dependent tree survival and relevant intra- and interspecific competition contribute to the regulation of tree populations in the forest. For most of common species, negative density-dependent mortality was rejected when trees exceeded $1 \mathrm{~cm}$ DBH. Generally, intraspecific competition was much stronger than interspecific competition for understory and midstory species. We emphasize that density dependence on tree survival changed with growth forms. Potential confounding factors, such as light and soil moisture, should be considered in studies that seek evidence for density dependence (He and Duncan, 2000). Meanwhile, there are still many questions lacking definitive answers. For example, little is known about the long-term effects of density dependence on tree establishment and survival in the temperate forest. Some studies in tropical and temperate forests 
suggested that density-dependent tree survival had its greatest impact on the earliest stages of plant establishment because of high susceptibility to herbivores, pathogens, and abiotic stresses (Dobbertin et al., 2001; Harms et al., 2000; Hyatt et al., 2003). Future studies will examine these environmental factors that have generated the patterns with sound experimental designs and long-term monitoring data. Such studies are a critical next step in understanding these roles of densitydependent tree survival in temperate forest communities.

Acknowledgements: We thank Drs. Fangliang He, Michael Papaik, and Hong Qian for constructive comments which greatly improved our study. This work was conducted while Jian Zhang was visiting Department of Renewable Resources, University of Alberta in 2007. Funding was provided by National Natural Science Foundation of China (30870400 and 30700093), National Key Technologies R\&D Program (2006BAD03A09), and K.C. Wong Education Foundation of Hong Kong.

\section{REFERENCES}

Condit R., 1998. Tropical forest census plots: methods and results from Barro Colorado Island, Panama and a comparison with other plots, Springer, Berlin.

Condit R., Ashton P.S., Baker P., Bunyavejchewin S., Gunatilleke S., Gunatilleke N., Hubbell S.P., Foster R.B., Itoh A., LaFrankie J.V., Lee H.S., Losos E., Manokaran N., Sukumar R., and Yamakura T., 2000. Spatial patterns in the distribution of tropical tree species. Science 288: 1414-1418.

Connell J.H., Tracey J.G., and Webb L.J., 1984. Compensatory recruitment, growth, and mortality as factors maintaining rain forest tree diversity. Ecol. Monogr. 54: 141-164.

Dobbertin M., Baltensweiler A., and Rigling D., 2001. Tree mortality in an unmanaged mountain pine (Pinus mugo var. uncinata) stand in the Swiss National Park impacted by root rot fungi. For. Ecol. Manage. 145: 79-89.

Duncan R.P., 1991. Competition and the coexistence of species in a mixed Podocarp stand. J. Ecol. 79: 1073-1084.

Engelbrecht B.M.J., Comita L.S., Condit R., Kursar T.A., Tyree M.T., Turner B.L., and Hubbell S.P., 2007. Drought sensitivity shapes species distribution patterns in tropical forests. Nature 447: 80-83.

Getzin S., Dean C., He F., Trofymow J.A., Wiegand K., and Wiegand T., 2006. Spatial patterns and competition of tree species in a Douglasfir chronosequence on Vancouver Island. Ecography 29: 671-682.

Gratzer G. and Rai P.B., 2004. Density-dependent mortality versus spatial segregation in early life stages of Abies densa and Rhododendron hodgsonii in Central Bhuta. For. Ecol. Manage. 192: 143-159.

Grubb P.J., 1977. The maintenance of species-richness in plant communities: the importance of the regeneration niche. Biol. Rev. 52: 45-45.

Gunton R.M. and Kunin W., 2007. Density effects at multiple scales in an experimental plant population. J. Ecol. 95: 435-445.

Hao Z., Zhang J., Song B., Ye J., and Li B., 2007. Vertical structure and spatial associations of dominant tree species in an old-growth temperate forest. For. Ecol. Manage. 252: 1-11.

Harms K.E., Wright S.J., Calderon O., Hernandez A., and Herre E.A., 2000. Pervasive density-dependent recruitment enhances seedling diversity in a tropical forest. Nature 404: 493-495.

He F. and Duncan R.P., 2000. Density-dependent effects on tree survival in an old growth Douglas fir forest. J. Ecol. 88: 676-688.

Hubbell S.P. and Foster R.B., 1986. Biology, chance and history in the structure of tropical rainforest tree communities. In: Diamond J. and Case T.J. (Eds.), Community Ecology, Harper \& Row, New York, pp. 314-329.

Hubbell S.P., Condit R., and Foster R.B., 1990. Presence and absence of density dependence in a neotropical tree community. Philos. Trans. R. Soc. B 330: 269-281.
Hyatt L.A., Rosenberg M.S., Howard T.G., Bole G., Fang W., and Anastasia J., 2003. The distance dependence prediction of the Janzen-Connell hypothesis: a meta-analysis. Oikos 103: 590-602.

Janzen D.H., 1970. Herbivores and the number tropical forests. Am. Nat. 104: 501-528.

John R., Dattaraja H.S., Suresh H.S., and Sukumar R., 2002. Densitydependence in common tree species in a tropical dry forest in Mudumalai, southern India. J. Veg. Sci. 13: 45-56.

John R., Dalling Y.W., Harms K.E., Yavitt J.B., Stallard R.F., Mirabello M., Hubbell S.P., Valencia R., Navarrete H., Vallaejo M., and Fosters R.B., 2007. Soil nutrients influence spatial distributions of tropical tree species. Proc. Natl. Acad. Sci. USA 104: 864-869.

Kenkel N.C., 1988. Pattern of self-thinning in Jack Pine: testing the random mortality hypothesis. Ecology 69: 1017-1024.

King D.A., Wright S.J., and Connell J.H., 2006. The contribution of interspecific variation in maximum tree height to tropical and temperate diversity. J. Trop. Ecol. 22: 11-24.

Koukoulas S. and Blackburn G.A., 2005. Spatial relationships between tree species and gap characteristics in broad-leaved deciduous woodland. J. Veg. Sci. 16: 587-596.

Mitchell-Olds T., 1987. Analysis of local variation in plant size. Ecology 68: 82-87.

Newton P.F., and Jolliffe P.A., 1998. Assessing processes of intraspecific competition within spatially heterogeneous black spruce stands. Can. J. Forest. Res. 28: 259-275.

Pacala S.W., 1989. Plant population dynamic theory. In: Roughgarden J., May R.M., and Levin S.A. (Eds.), Perspectives in ecological theory, Princeton University Press, Princeton, pp. 54-67.

Peters H.A., 2003. Neighbour-regulated mortality: the influence of positive and negative density dependence on tree populations in speciesrich tropical forests. Ecol. Lett. 6: 757-765.

Ripley B.D., 1981. Spatial Statistics, Wiley, New York, p. 252

Salas C., LeMay V., Núñez P., Pacheco P., and Espinosa A., 2006. Spatial patterns in an old-growth Nothofagus obliqua forest in south-central Chile. For. Ecol. Manage. 231: 38-46.

Silvertown J. and Charlesworth D., 2001. Introduction to plant population biology. 4th ed., Blackwell Science, Oxford.

Stoyan D. and Stoyan H., 1994. Fractals, random shapes and point fields, Wiley, Chichester.

Volkov I., Banavar J.R., He F., Hubbell S.P., and Maritan A., 2005. Density dependence explains tree species abundance and diversity in tropical forests. Nature 438: 658-661.

Wallace Z.P., Lovett G.M., Hart J.E., and Machona B., 2007. Effects of nitrogen saturation on tree growth and death in a mixed-oak forest. For. Ecol. Manage. 243: 210-218.

Wiegand T. and Moloney K.A., 2004. Rings, circles and null-models for point pattern analysis in ecology. Oikos 104: 209-229.

Wills C. and Condit R., 1999. Similar non-random processes maintain diversity in two tropical rainforests. Philos. Trans. R. Soc. B 266: 1445-1452.

Wills C., Condit R., Foster R.B., and Hubbell S.P., 1997. Strong densityand diversity-related effects help to maintain tree species diversity in a neotropical forest. Proc. Natl. Acad. Sci. USA 94: 1252-1257.

Wills C., Harms K.E., Condit R., King D., Thompson J., He F., Muller-Landau H.C., Ashton P., Losos E., Comita L., Hubbell S.P., LaFrankie J., Bunyavejchewin S., Dattaraja H.S., Davies S., Esufali S., Foster R., Gunatilleke N., Gunatilleke S., Hall P., Itoh A., John R., Kiratiprayoon S., de Lao S.L., Massa M., Nath C., Noor M.N.S., Kassim A.R., Sukumar R., Suresh H.S., Sun I.F., Tan S., Yamakura T., and Zimmerman E., 2006. Nonrandom processes maintain diversity in tropical forests. Science 311: 527.

Xu H., 2001. Natural forests of Pinus Koraiensis in China, China Forestry Publishing House, Beijing.

Yang H., Li D., Wang B., and Han J., 1985. Distribution patterns of dominant tree species on northern slope of Changbai Mountain. Research of Forest Ecosystem 5: 1-14.

Yang X. and Xu M., 2003. Biodiversity conservation in Changbai Mountain Biosphere Reserve, northeastern China: status, problem, and strategy. Biodivers. Conserv. 12: 883-903. 